\title{
Multiphase Induction Motor Drives for Gear-Less Electric Vehicle
}

\section{Applications}

${ }^{1}$ Prof. Atif Iqbal, ${ }^{2}$ Dr. M. Al-Hitmi and ${ }^{3}$ Asokan Paraprath

${ }^{1,2}$ Department of Electrical Engineering, College of Engineering, Qatar University, Doha, Qatar

3Siemens WLL, Doha, Qatar

Email: ${ }^{1 a t i f . i q b a l @ q u . e d u . q a, 2 m . a . a l h i t m i @ q u . e d u . q a ~ a n d ~ 3 a s o k a n . p a r a p r a t h @ s i e m e n s . c o m ~}$

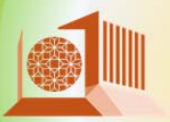

كلية الهندسة College of Engineering QATAR UNIVERSITY
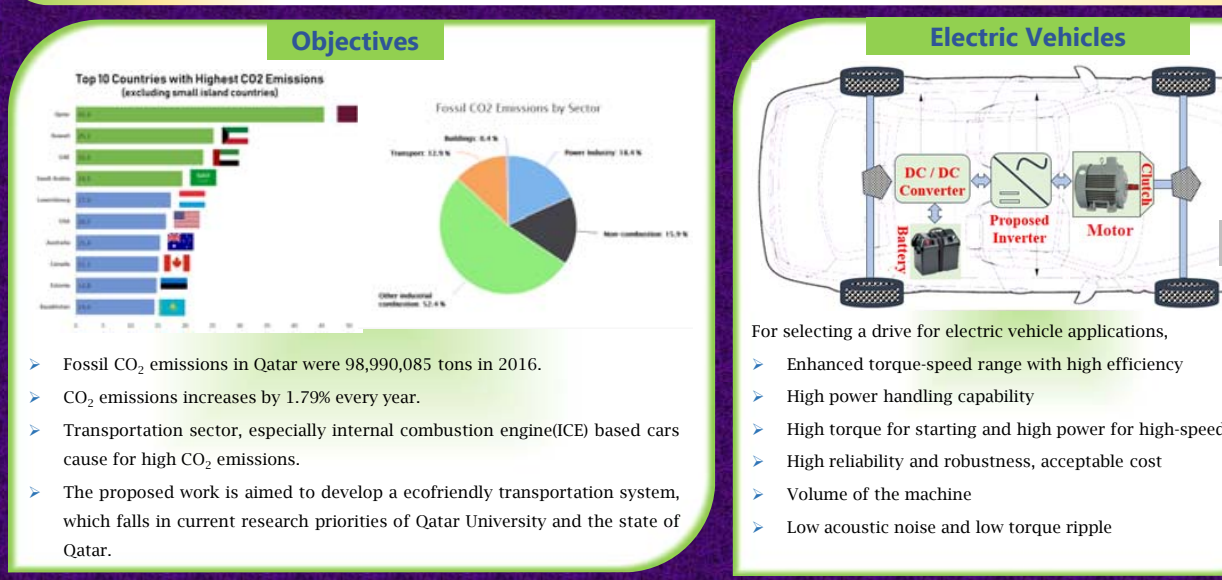

For selecting a drive for electric vehicle applications,

Enhanced torque-speed range with high efficiency

High power handling capability

High torque for starting and high power for high-speed cruising

High reliability and robustness, acceptable cost

Volume of the machine

Low acoustic noise and low torque ripple

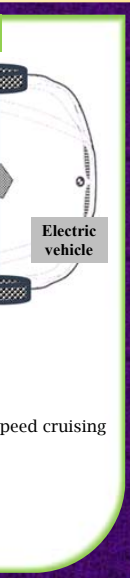

Why Multi-Phase Machines??

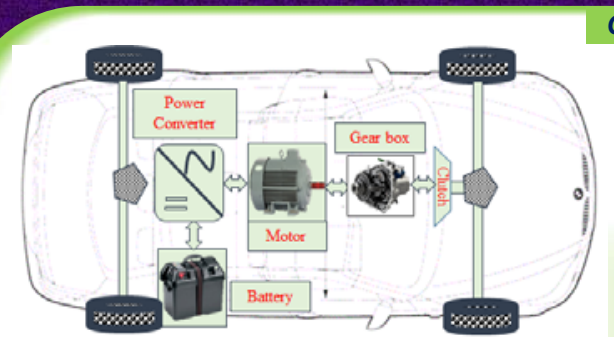

Conventional Three Phase Induction Motor Drive for EV

Overview of Electric Vehicle with 3-phase Induction Motors

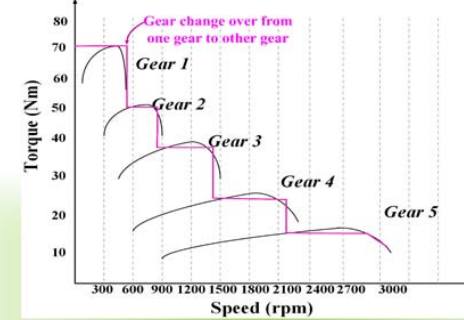

Gear box is required

High DC
series

Lower reliability
number of phases

Efficiency is low

High ratings of devices required

Higher size of machine, higher number of batteries, requirement of gear

Torque and Speed Characteristics of the Drive

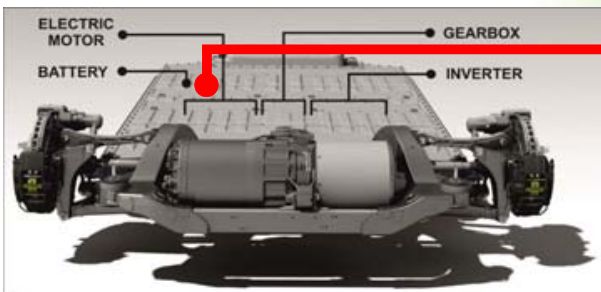

Tesla Motor Drive system for EV with 3-phase IM
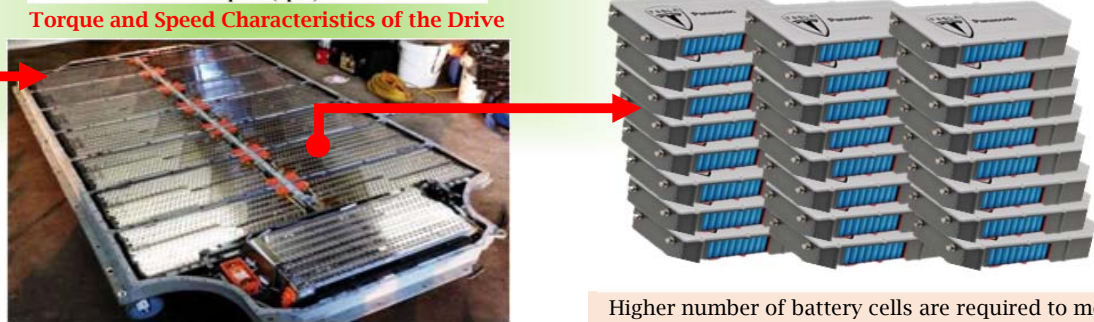

Higher number of battery cells are required to meet Tesla Motor Drive Battery system the $600 \mathrm{~V}$ DC bus to drive the 3-phase IM drive

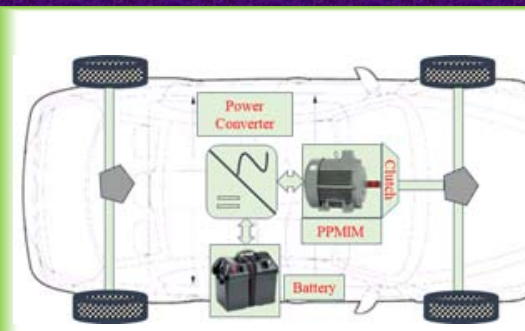

Overview of Electric Vehicle with multiphase Induction Motors

\section{Multiphase Induction Motor Drive for Gearless EV}

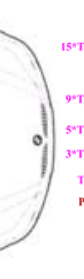

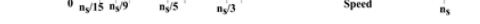

Torque and Speed Characteristics of Pole Phase Modulated IM Drive

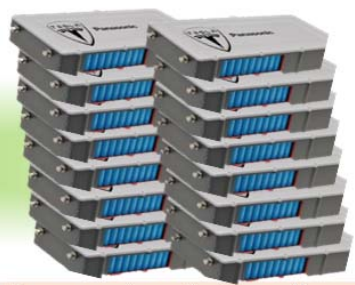

Lesser number of battery cells are required to meet the $120 \mathrm{~V} \mathrm{DC}$ bus
With Multiphase Phase Induction Motor Gear box is eliminated because the machine itself providing enhanced torque speed profile similar to IC engine

Higher reliability due to the parallel connected batteries and higher number of phase Efficiency is high

Lower DC link Voltage

Better power distribution/phase

Reduced ratings of devices required

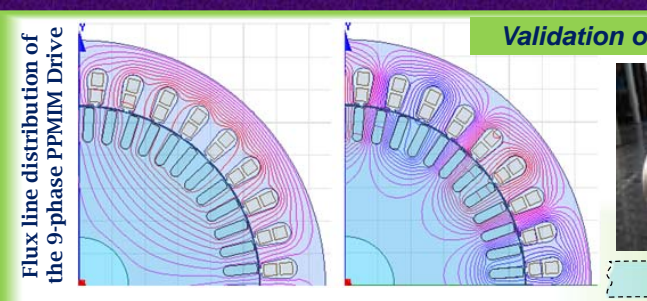

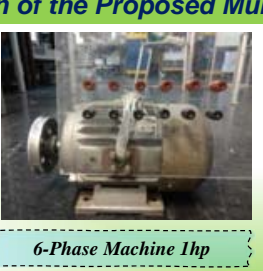

6-Phase Machine $1 \mathrm{hp}$
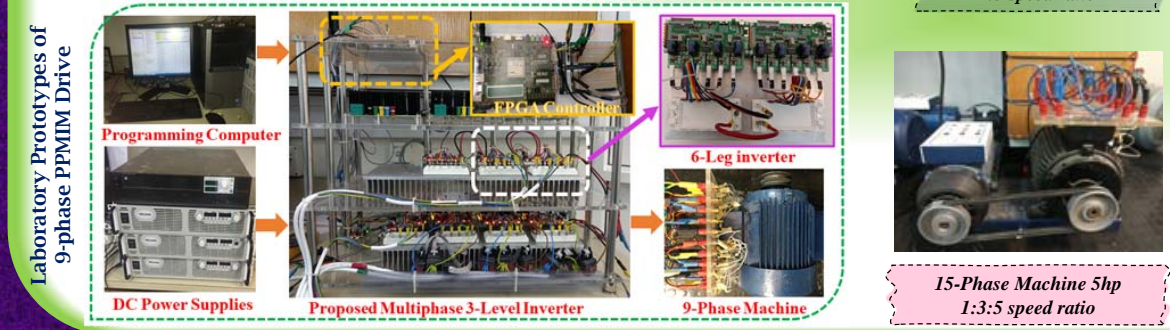

15-Phase Machine 5hp
1:3:5 speed ratio

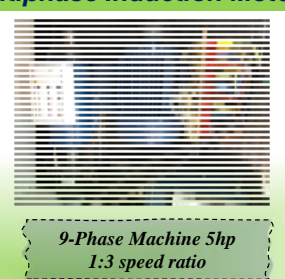

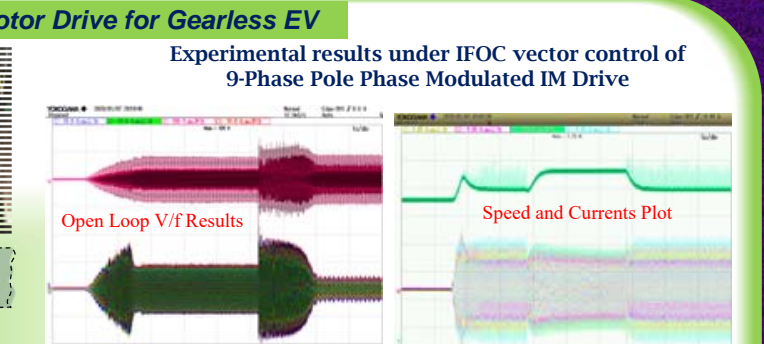

xperimental results under IFOC vector control of 